\title{
ANALYTICAL STUDY OF THE SAFETY ISSUES FOR CHILDREN IN THE LOW INCOME NEIGHBORHOOD STREETS IN RIYADH, SAUDI ARABIA
}

\section{Dr. Omar S. BaHammam \\ College of Architecture and Planning King Saud Univeristy oshammam@gmail.com}

(Received December 1, 2006 Accepted December 16, 2006)

Cities give serious attentions to designing their streets and lay them out to provide for the safety of pedestrians on the road especially children. Existing street situation does not encourage pedestrians nor does it provide for the safety of users especially children.

The study looks at the existing situation of neighborhood streets with an analytical eye in regard to children safety and trying to determine the existing obstacles in relation to safety of children and the design of streetscape.

To address this issue, a fieldwork survey was conducted assess the existing situation in the randomly selected neighborhoods in the city and determine the safety challenges facing children in streets.

The main benefit of this research is to pull the attention to the issue and to set a new methodology for studying the issue of children safety and open a new frontier that is in urgent needs in our daily life.

دراسة تحليلية لمستوى الأمان للأطفال في شوارع الأحياء السكنية ذات الاخل المحدود في مدينة الرياض.
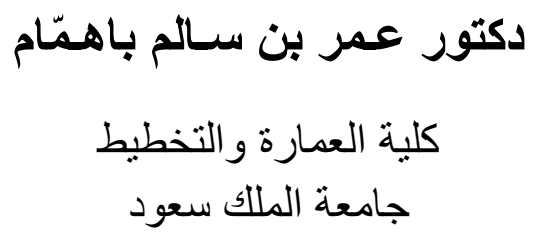

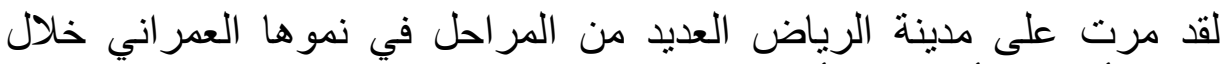

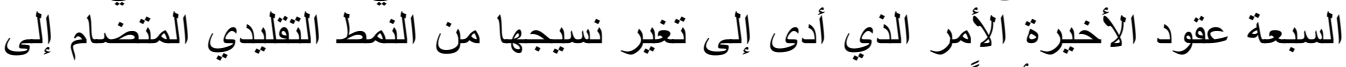
النمط الثبكي الممتد أفقياً. وقد تمددت المدينة في الفترة بين منتصف السبعينات وبداية 
الثمانينات من القرن الميلادي الماضي بشكل ملحوظ كنتيجة مباشرة للتحسن

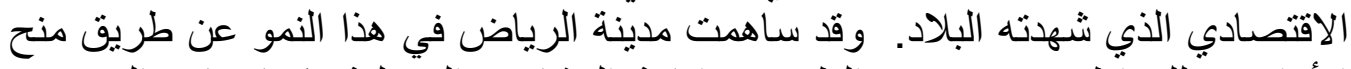

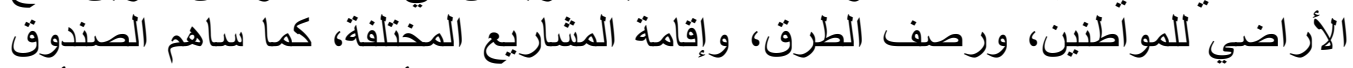

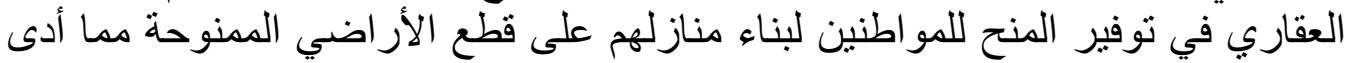

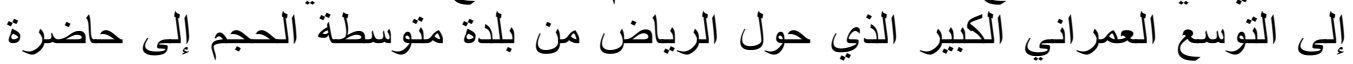
كبيرة.

ومع هذا التغير والتحول العمراني ظهر ات أنماط الثوار ع و الطرقات مختلفة كل

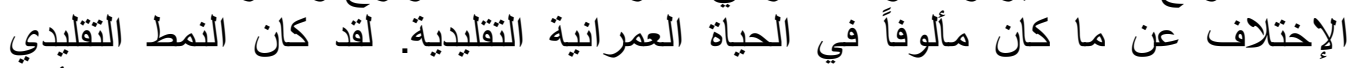

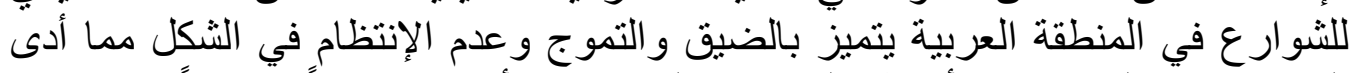

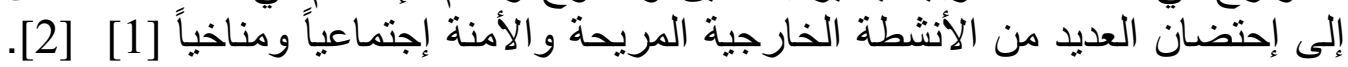

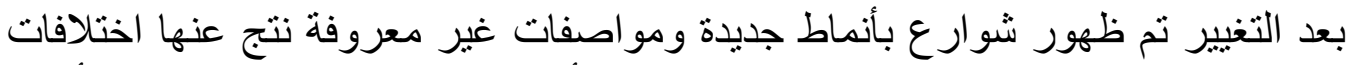

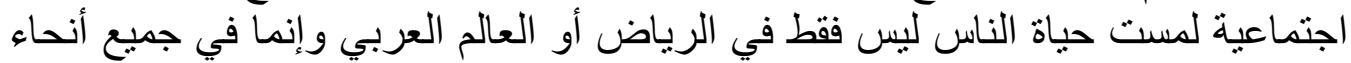

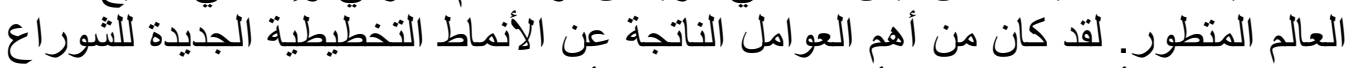

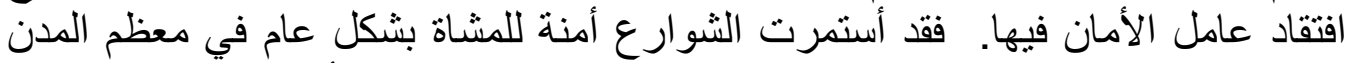

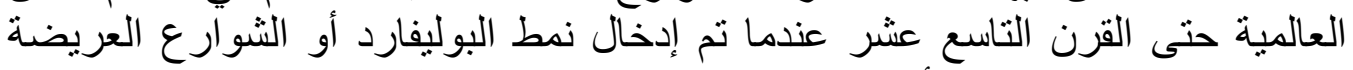

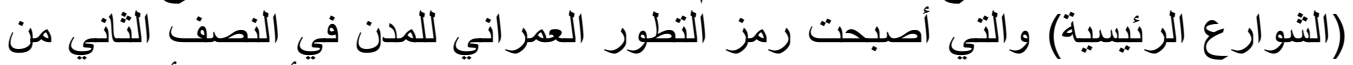

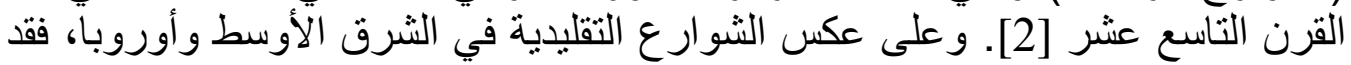

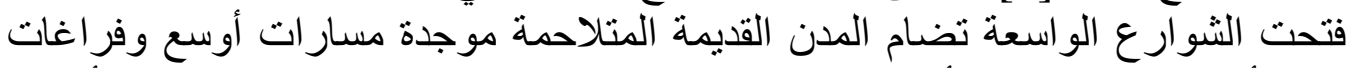

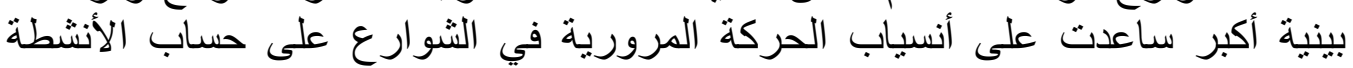

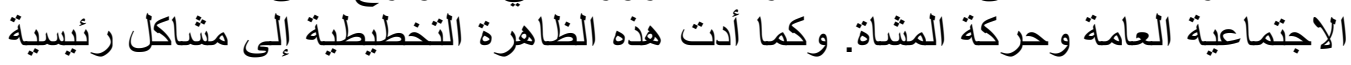

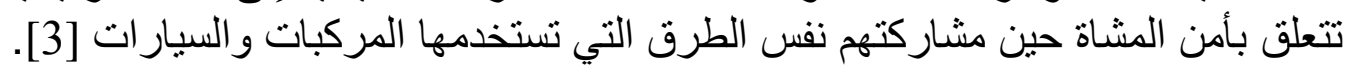

لقد تعاقب على مدينة الرياض في مر احل نمو ها مخططون غربيون قادوا تطور

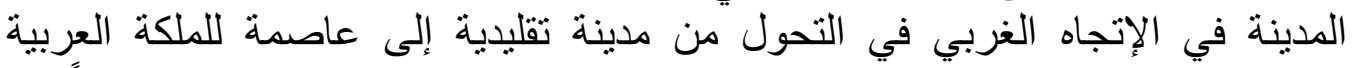

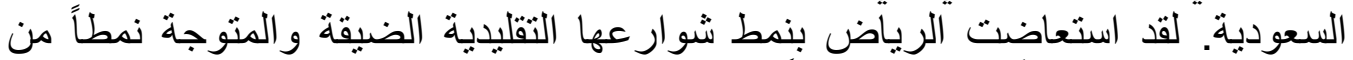

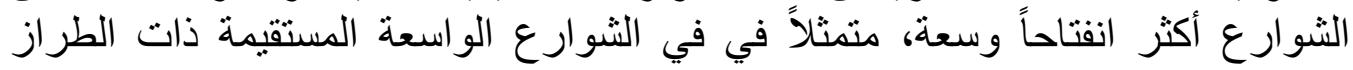
الثبكي الذي يحاكي مثنيلاتها من المدن الصنأَية الكية الكبيرة في العالم.

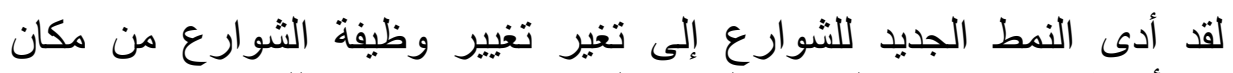

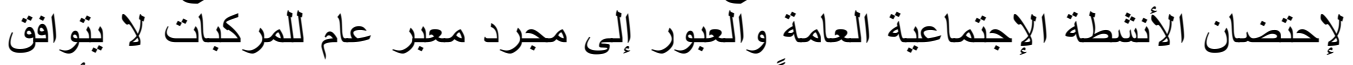

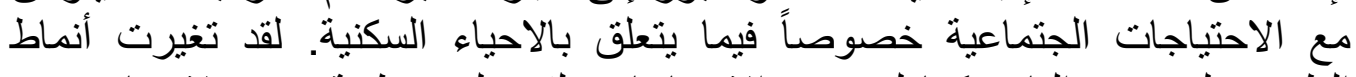

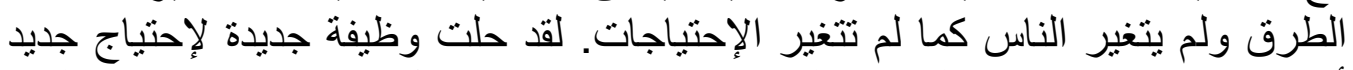

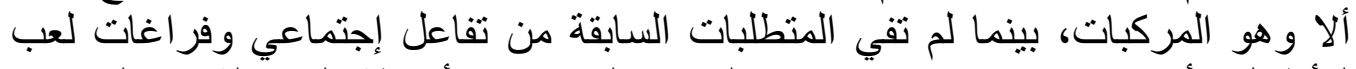

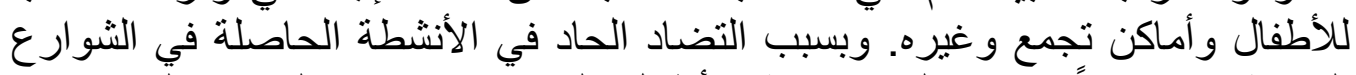

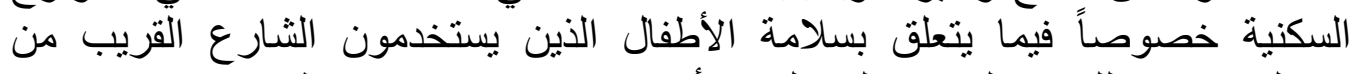
منازلهم كمكان للعب و المرح و التفاعل مع أقرانهم من بني جير انهم ظهر تحد جديد يكمن لأنس 
في الخطر المهدد لحياتهم بسبب الأتصال المباثر بين أنشطتهم والنشاط الحيوي الجديد

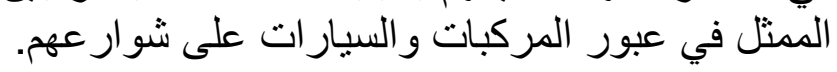

\section{2 - أهداف البحث ومنهجيته:}

مع توسع مدينة الرياض وتحولها من مدينة عربية تقليدية إلى عاصمة حضرية الماكية

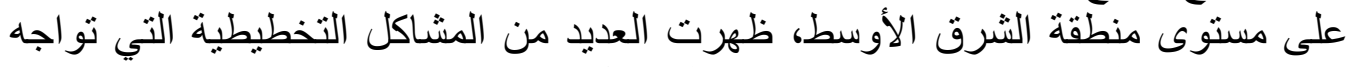

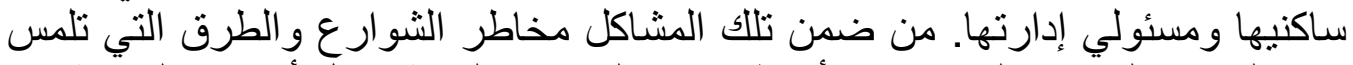

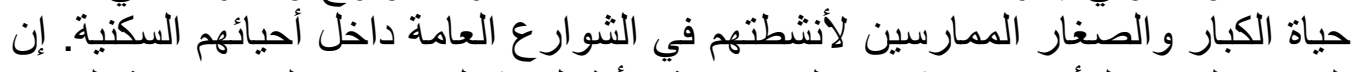

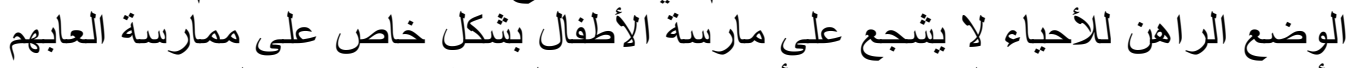

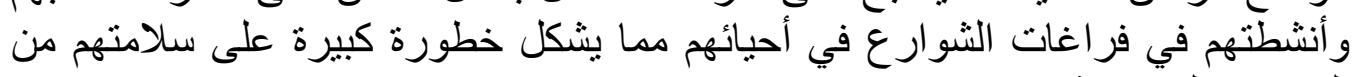
الحو ادث المرورية.

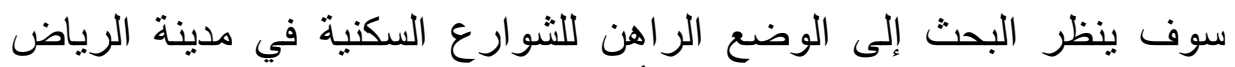

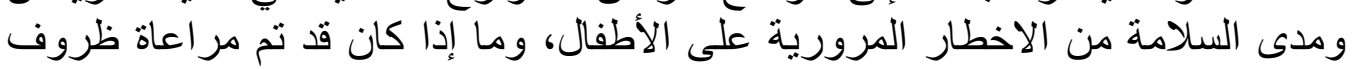

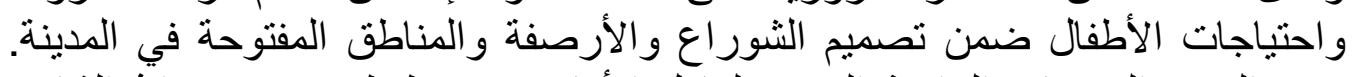

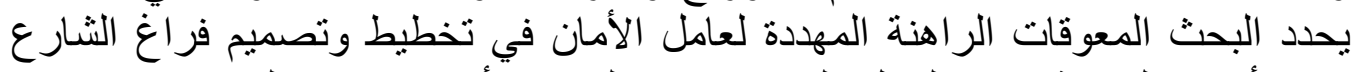

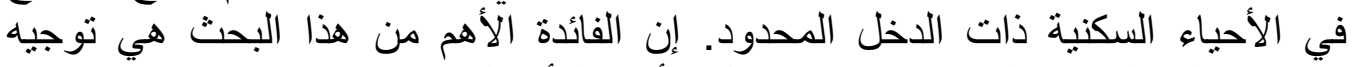

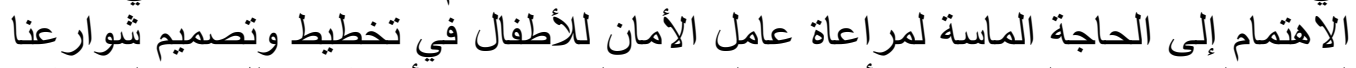

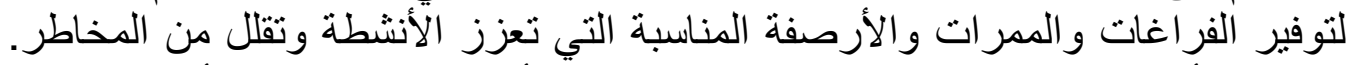

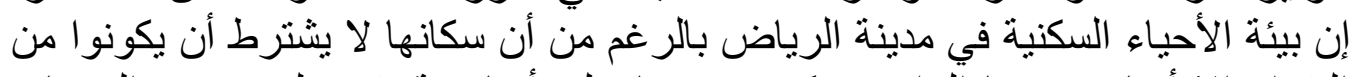

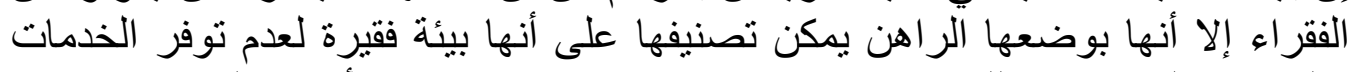

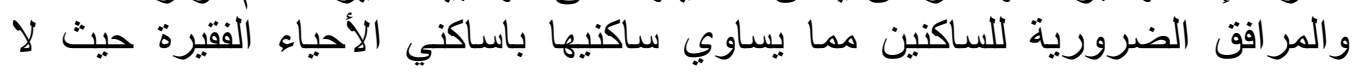
يختلف الوضع من الناحية الفر اغية و التخيطيطة بين البئينين.

يهدف البحث إلى التعرف على المشاكل الرئيسية التي تهدد أمان الأطفال في تئي

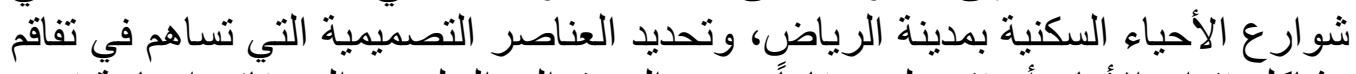

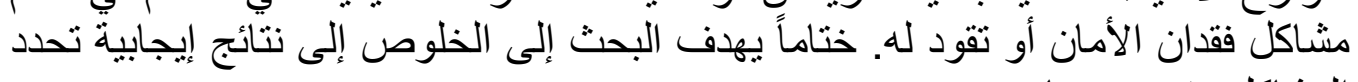

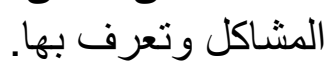

يقوم البحث على تعريف الموضوع فيما يرتبط بعو امل أمان للمشاة والأطفال

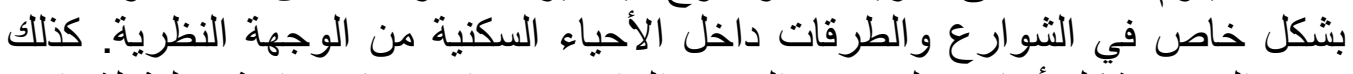

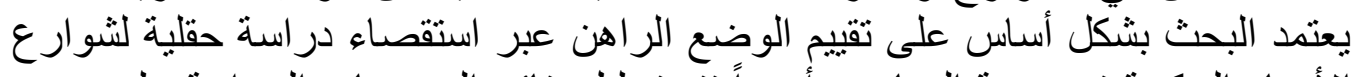

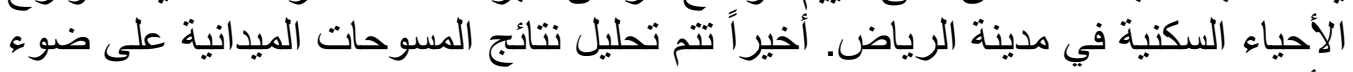

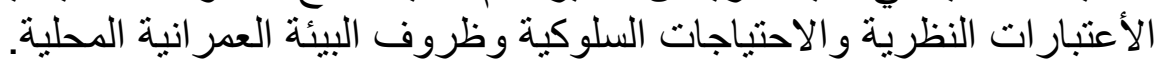




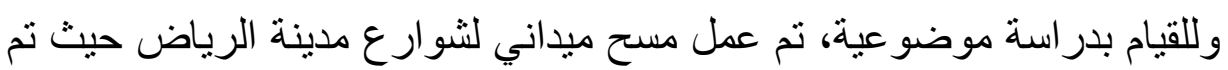

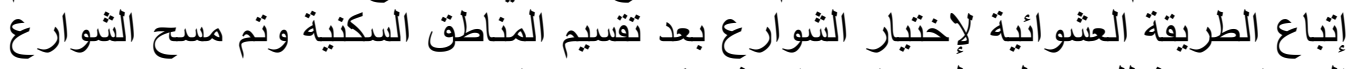
المختارة بدقة للحصول على نتائج و اقعية يمكن تعميمها.

\section{3 الوضع الراهن للشوارع:}

في خضم النهضة العمرانية التي شهدتها الرياض في العقود الأخيرة لم تهتم

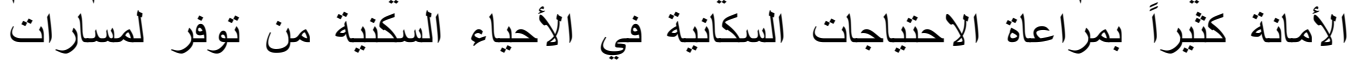

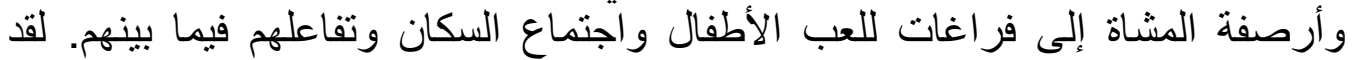

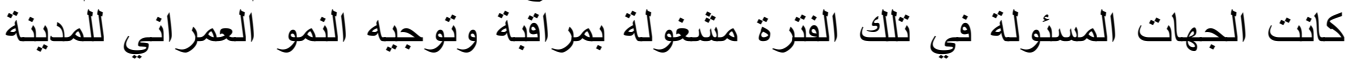

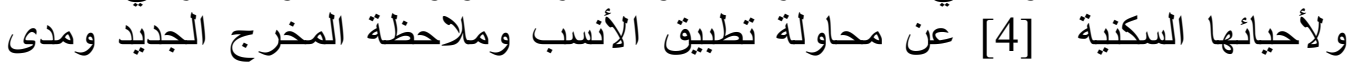
ملائمته للإحتياج.

لقد أنشئت الشوارع على أساس النظام الشبكي الذي يقوم على فكرة الثوارع

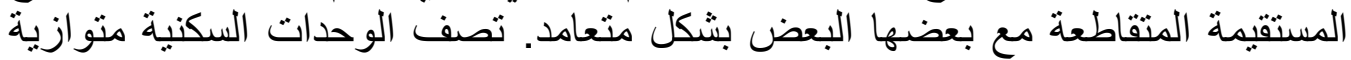

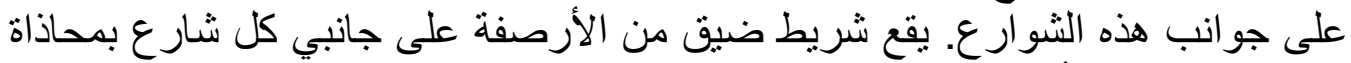
الوحدات السكنية (أنظر الثكل رؤ رقم 1).

لقد حددت الجهات المعنية بتخطيط المدينة خمسة أصناف للشوارع في في مدينة

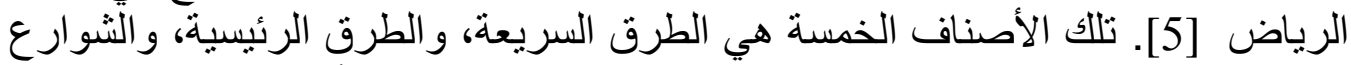

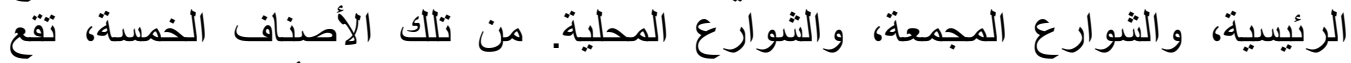

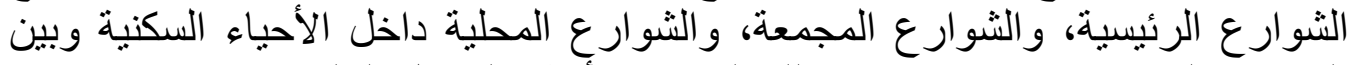
الوحدات السكنية. تنراوح عروض والثن تلك الثوارع (أنظر الجدول التالي): جدول رقم (1) يوضح عروض الثوار ع داخل الاحياء السكنية.

\begin{tabular}{|c|c|}
\hline العرض & الصنف \\
\hline 60-40 متر & الثوارع الرئيسية \\
\hline 20-40 متر & الثو ارع المجمعة \\
\hline 20 متر & الثوار ع المحلية \\
\hline
\end{tabular}


4 - عامل الأمان والمشكلات الراهنة:

من المعلوم بدهياًً في مدننا العربية أن الأحياء السكنية هي أماكن مخصصة الاكية

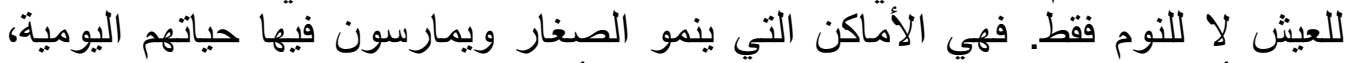

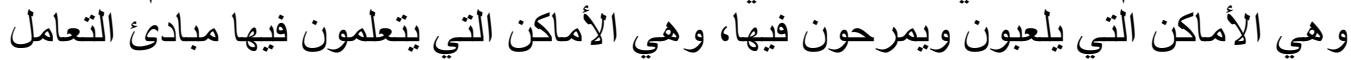

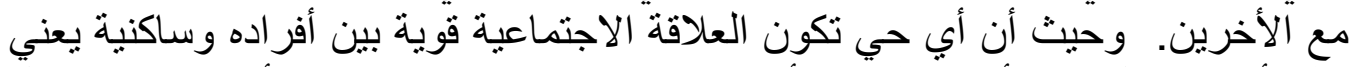

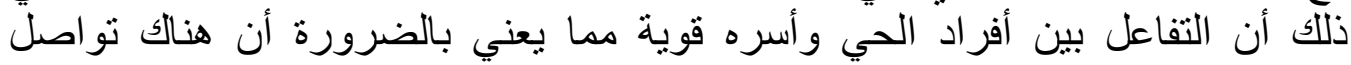

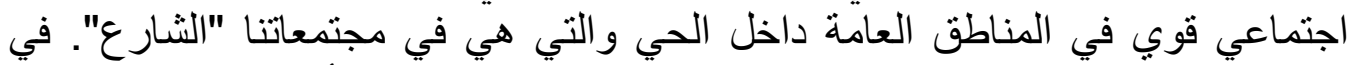

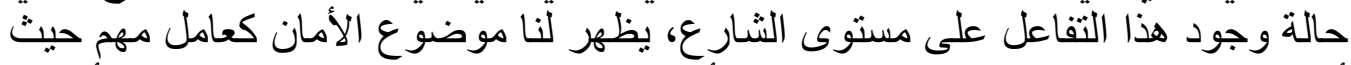

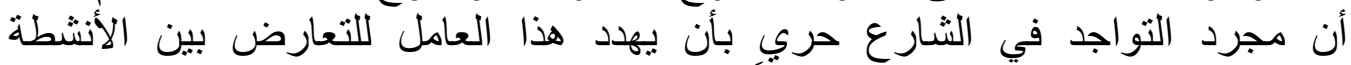

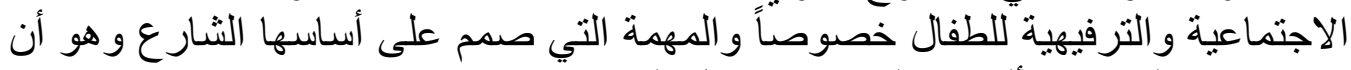
يكون مسار لحركة الأليات و السيار ات داخل المدينة.

كثير من الدراسات ناقثت عامل الأمان خصوصاً فيما يتعلق بالأطفال داخل

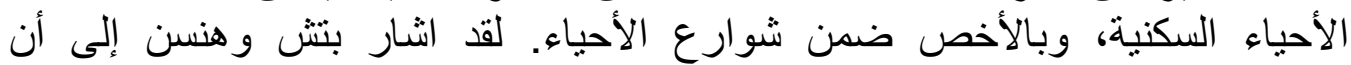

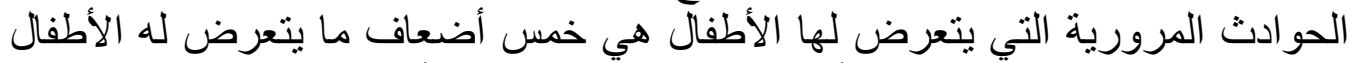

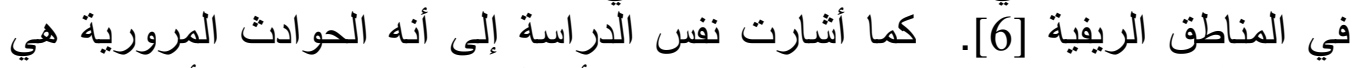

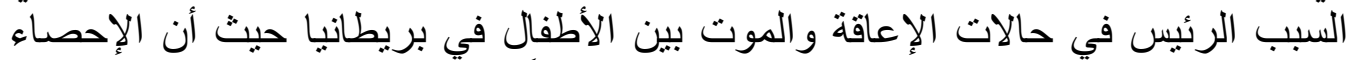

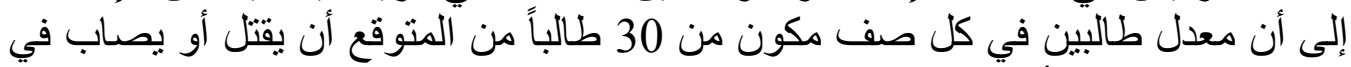

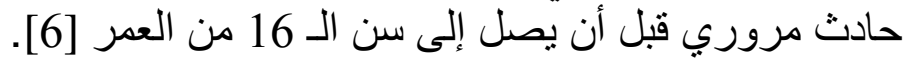

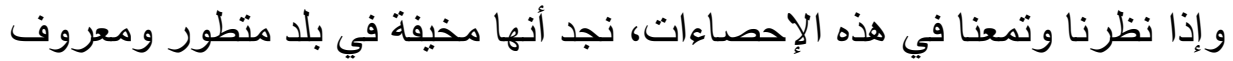

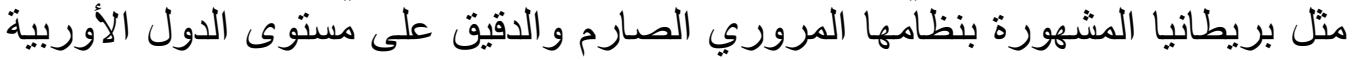

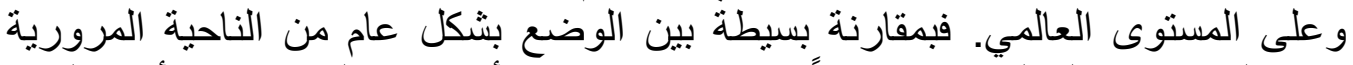

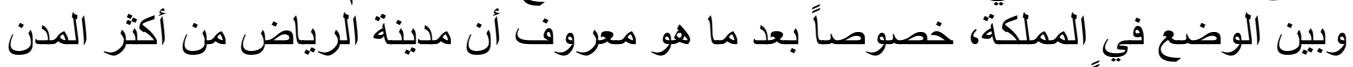

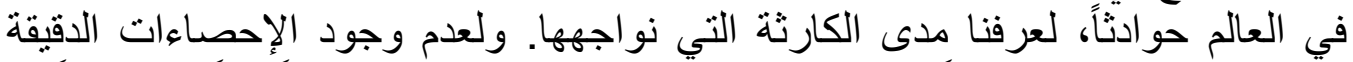

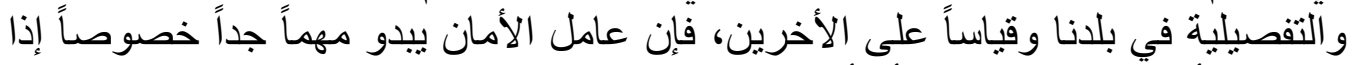

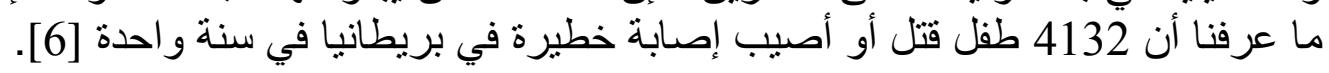

ولتحديد أسباب فقدان عامل الأمان للأطفال نجد أن هناك العديد من الدراسات

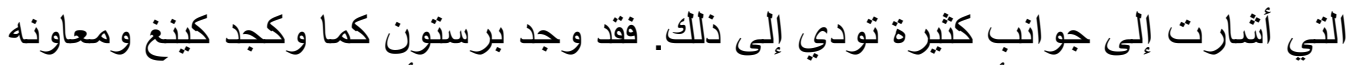

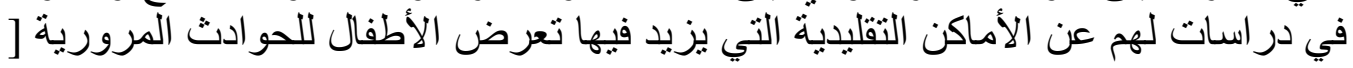

• أنواع معينة من الوحدات السكنية (ويعني بها الوحدات السكنية ذات الطراز

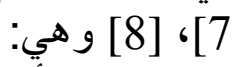
الفكتوري ذات الفناء الأمامي).

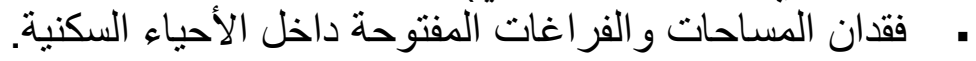

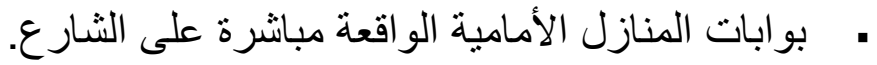


• كثرة السيار ات الواقفة بمحاذات رصيف المشاة في الأحياء.

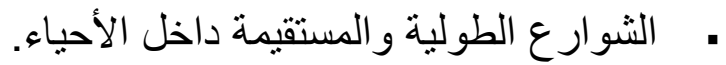

• المستوى العالي من الحركة العابرة داخل الأحياء.

وفي مدينة مثل مدينة الرياض وبالوصف الذي تم تقديمة للبيئة الحالية للأحياء السكنية، نجد أنها تفتقد إلى الكثير من المقومات المهمة المتعلقة بالمشاة وأنشطتهم القائمة

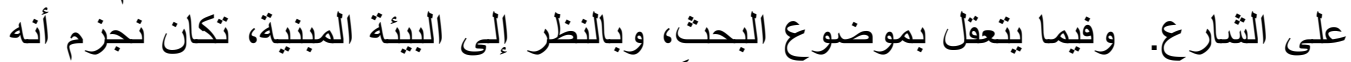

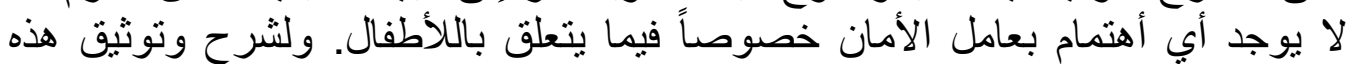

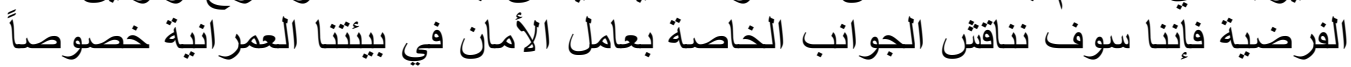

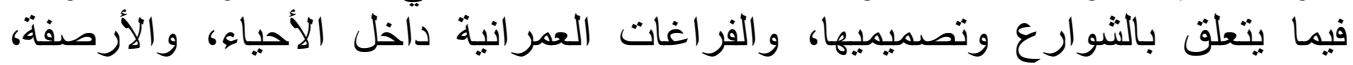
ووضعية الوحدات السكنية، و علاقتها بالطريق و وغيره من الجوات انب ذات ذات العلاقة.

\section{1-4 - تخطيط الشارع في الحي السكني:}

كان البعد عن النمط العربي لتخطيط المدينة واضح في أول مخطط لمدينة

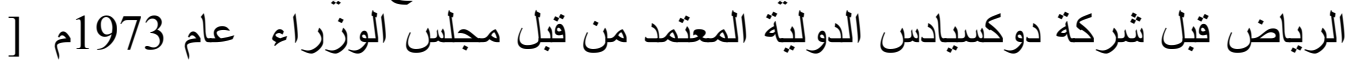

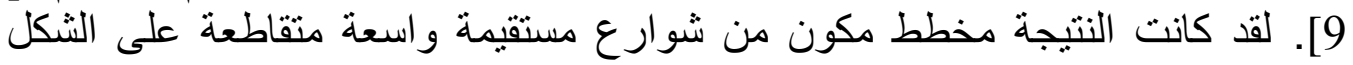

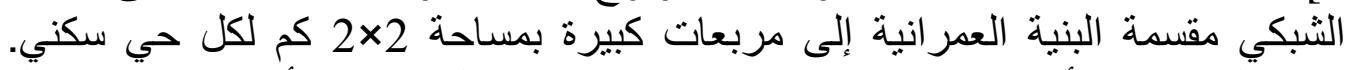

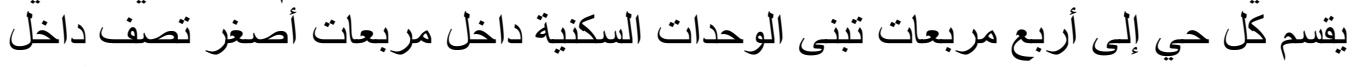

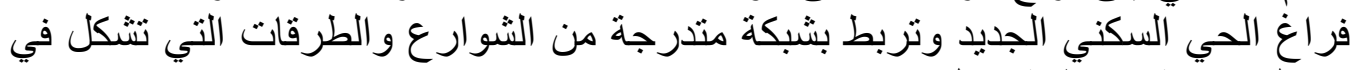

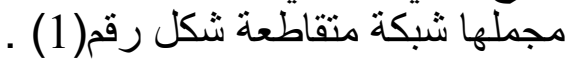

وكنتيجة لهذا النمط الجديد ظهرت لدينا المعطيات التالية داخل الأحياء السكنية

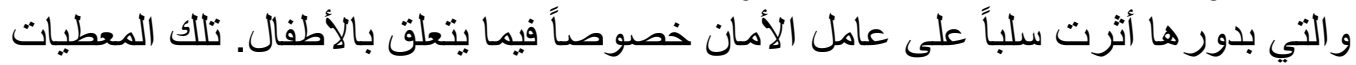

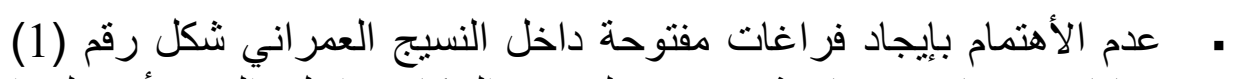
هي:

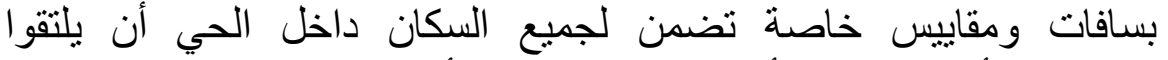

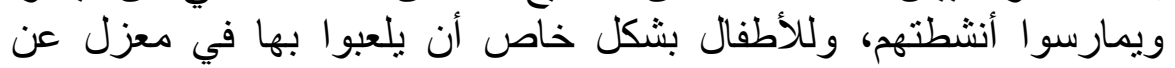

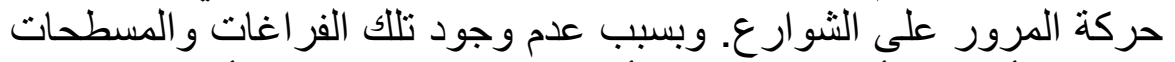

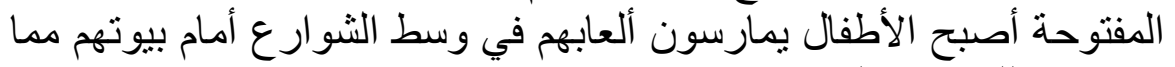
يعرضهم للحو ادث المرورية.

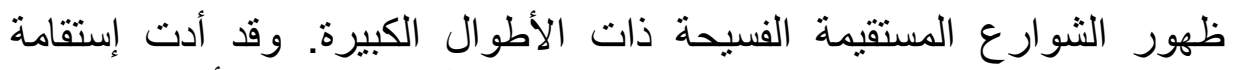

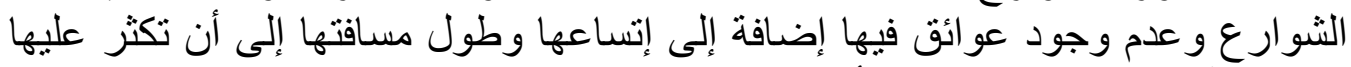

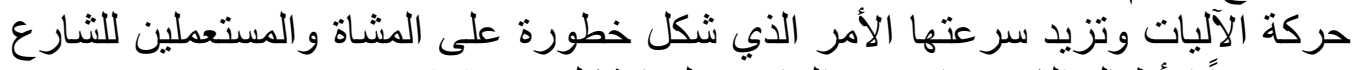
خصوصاً الأطفال الذين يمارسون العابهم عليها شكل رقم الأبر (2). 


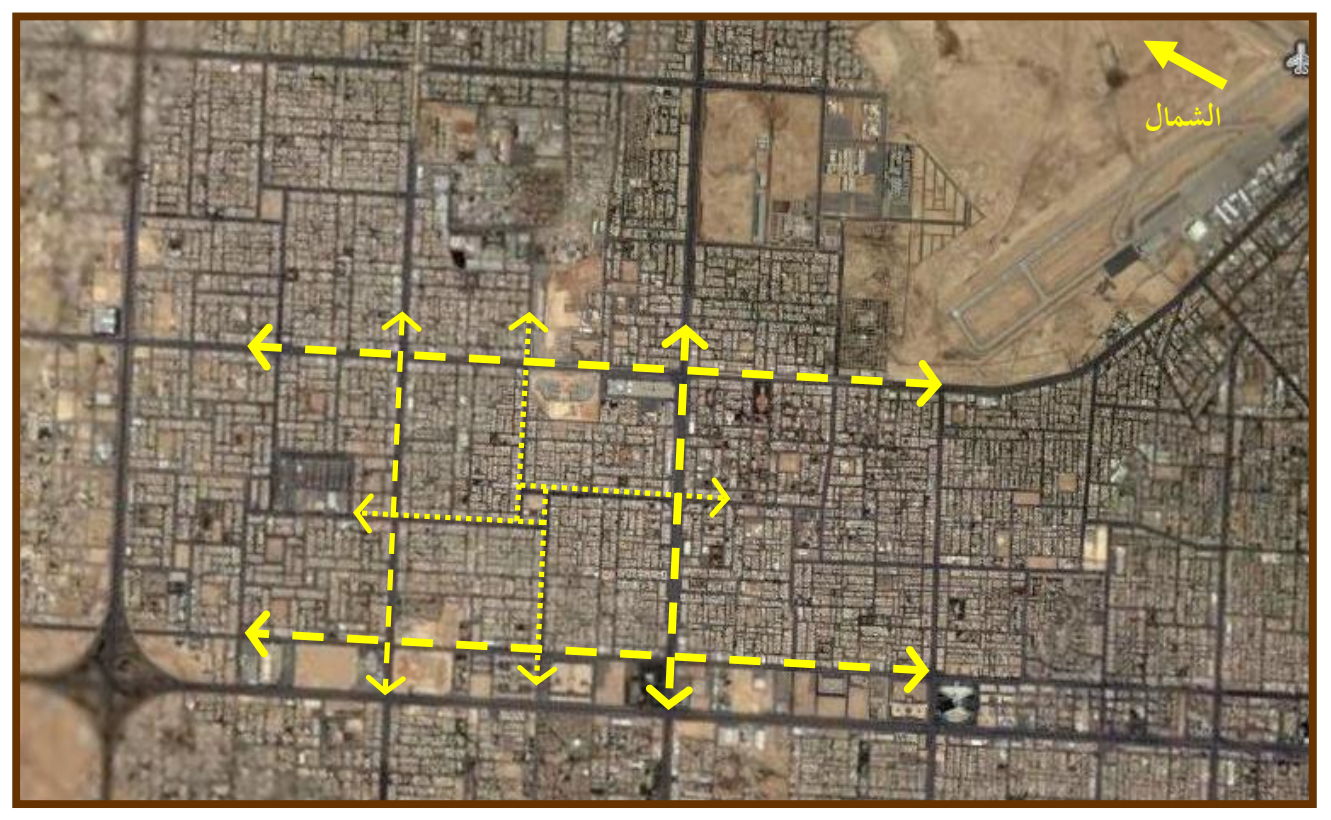

الثكل رقم (1) صورة جوية توضح النمط المتبنى كأساس للتخطيط في مدينة الرياض.

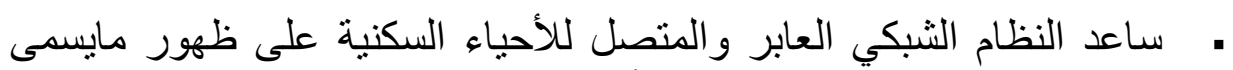

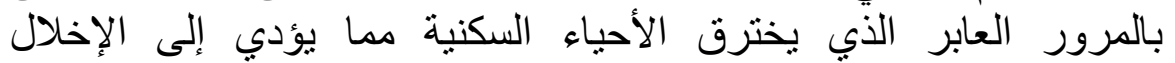

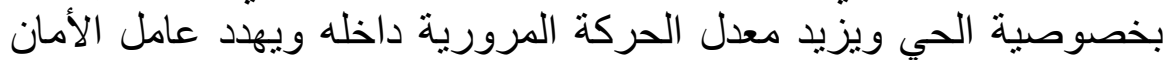

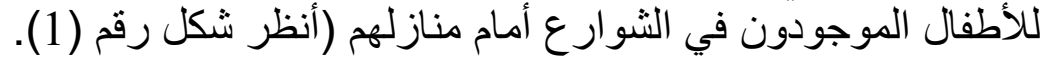

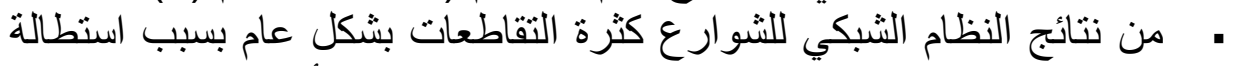

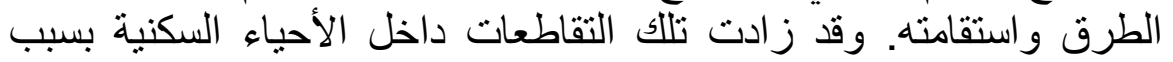

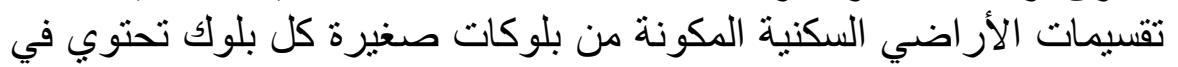

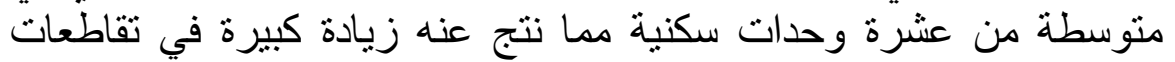
الطرق داخل تللك الأحياء. تشكل التقاطعات خطورة كبيرة

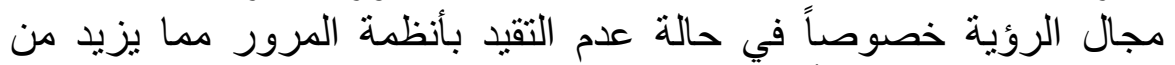
احتمالية تهديد عامل الأمان شكل شئ رقم (3). 


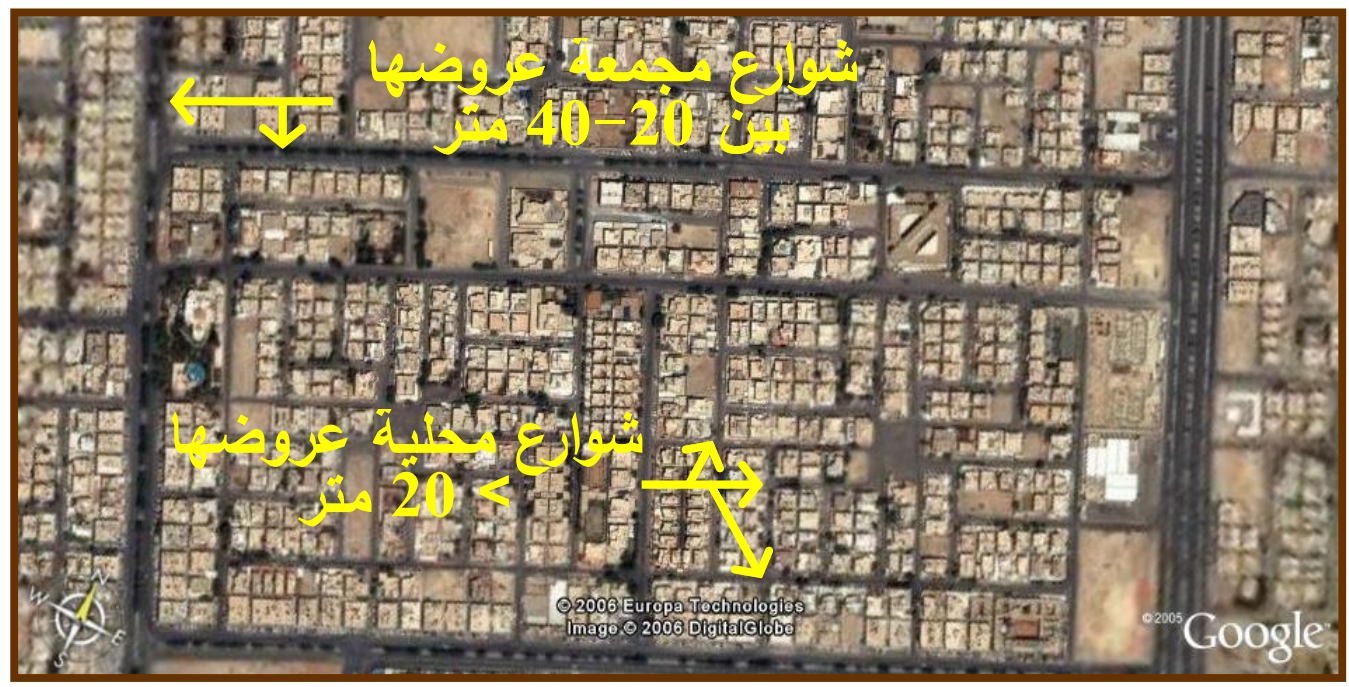

الثكل رقم(2) صورة جوية توضح استقامة واستطالة الشوارع في الأحياء السكنية واتساعها.

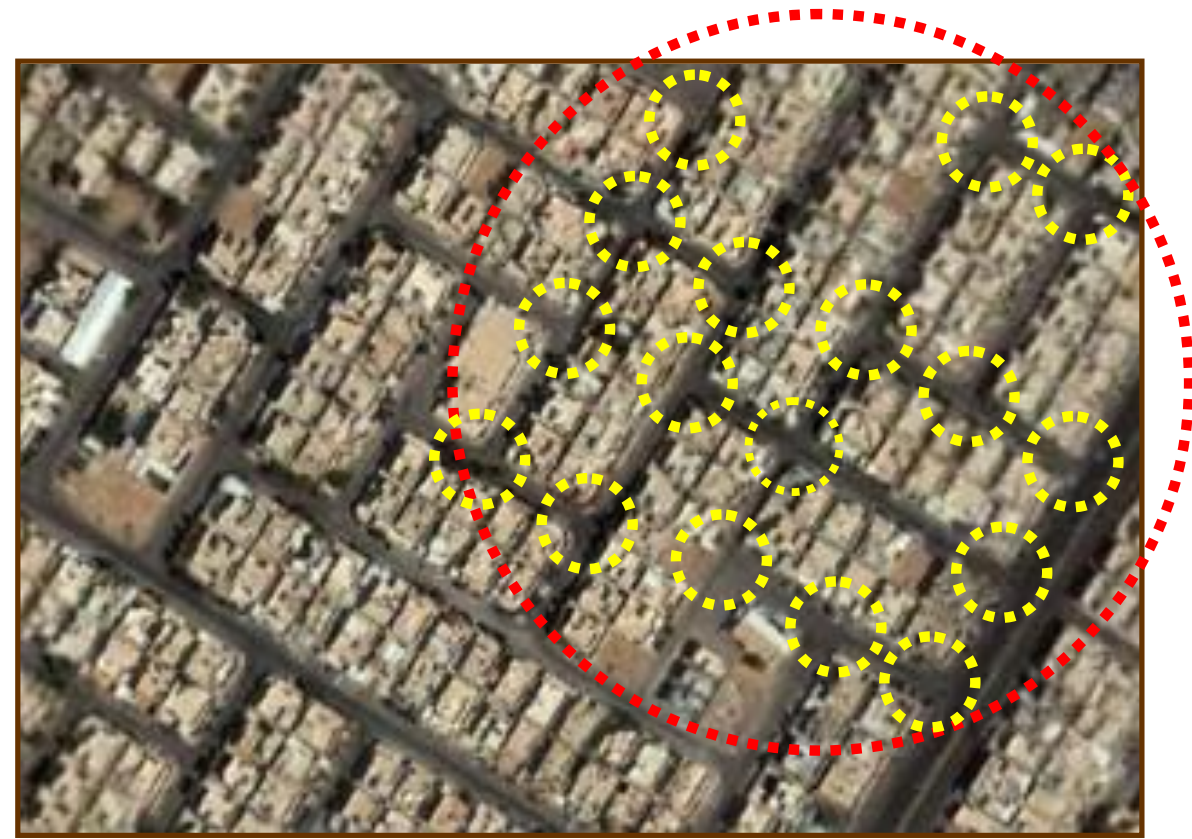

الثكل رقم(3) صورة جوية توضح كثرة التقاطعات ضمن الدائرة في جزء من حي سكني.

2-4 - تصميم أرصفة وممرات المشاة:

من المسح الميداني يتضح لنا أن هناك خصائص تجمع بين جميع تصنيفات

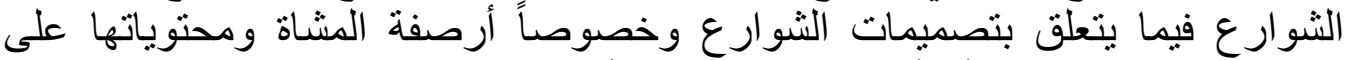

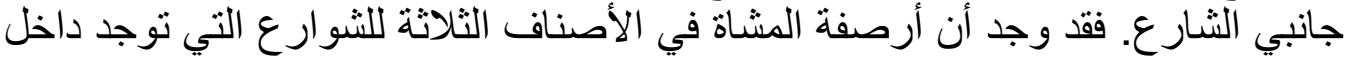


الأحياء السكنية (وهي الثوارع الرئيسية، والثوارع المجمعة، و الثوارع المحلية)

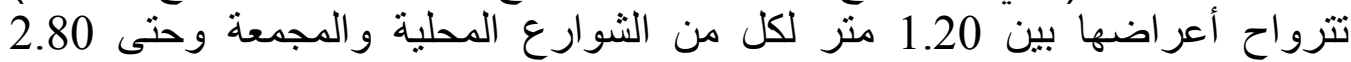

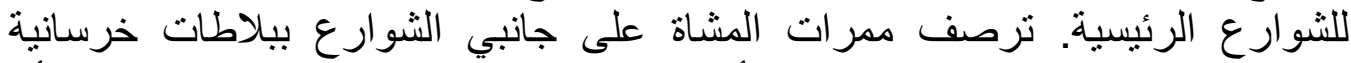

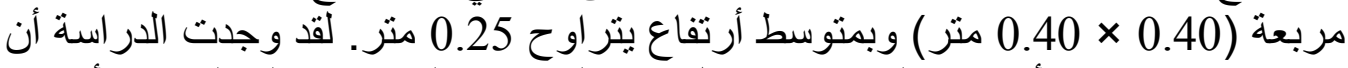

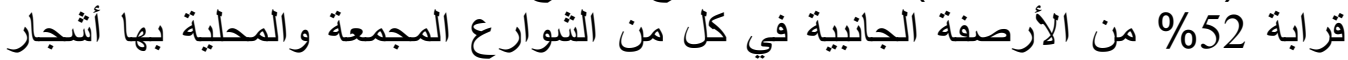

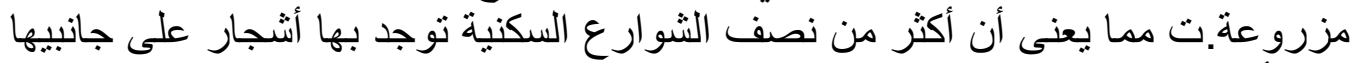

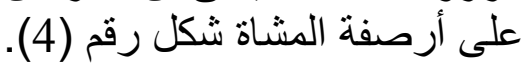

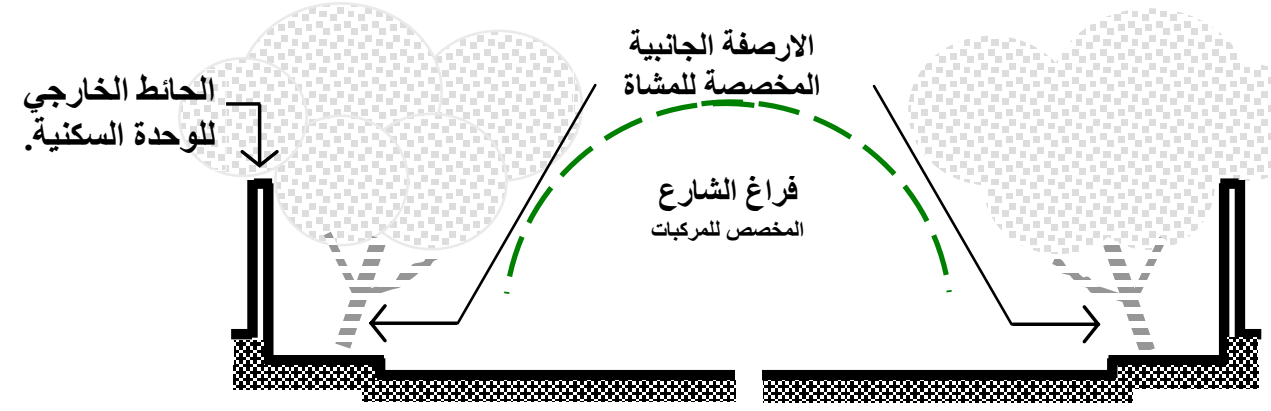

الثكل رقم (4) مقطع تجريدي يوضح مكان أرصفة الششاة في الأحياء السكنية

$$
\text { وعلاقتها بالوحدات السكنية وفراغ الثنارع. }
$$

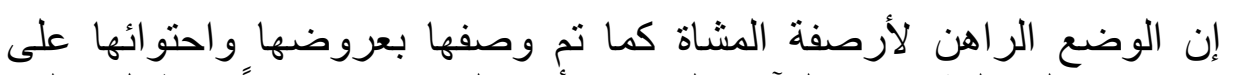

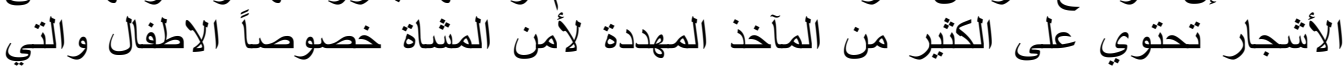

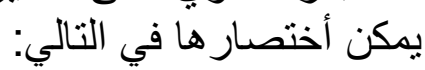
• عرض الرصيف بوضعة الحالي 1.20 متر في الثوارع المجمعة والمحلية غير كافي للأطفال للعب أو ممارسة أنشطتهم.

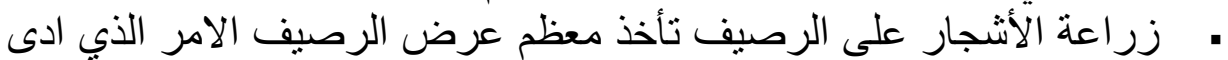

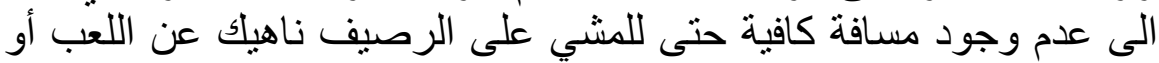
الجري مما يضطرهم إلى ممارسة أنشطتهم على ظهر الطريق نالى شكل رقم

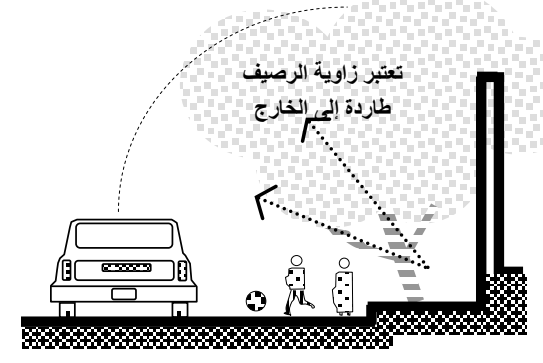

الثكل رقم (5) مقطع تجريدي يوضح التهديدات الأمنية التي تواجه الأطفال في الأحياء السكنية بلعهم مع على مسارات حركة المرور . 


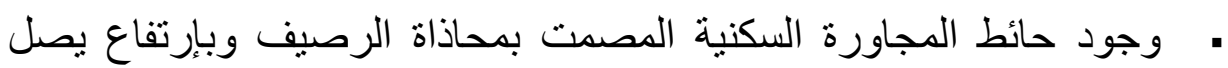

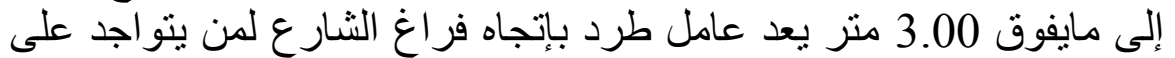

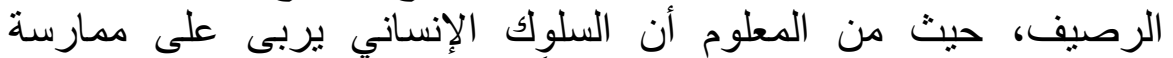

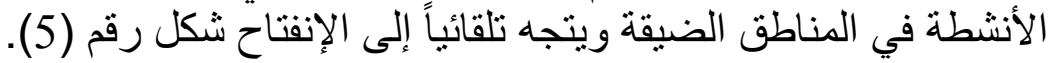

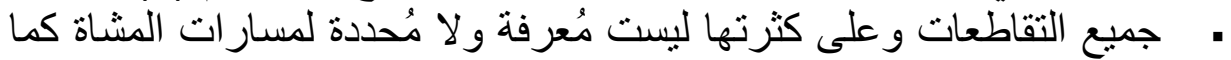

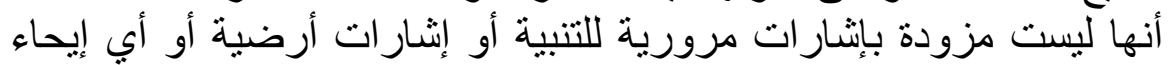

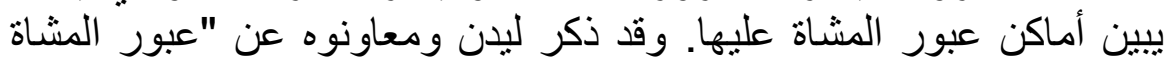

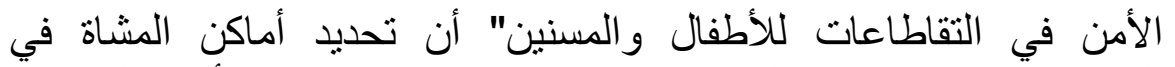

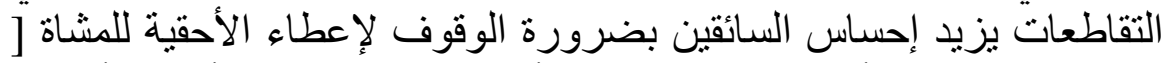

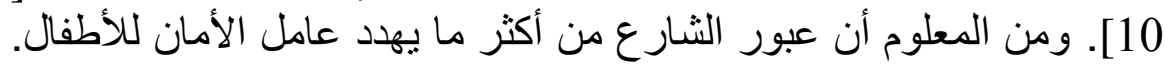

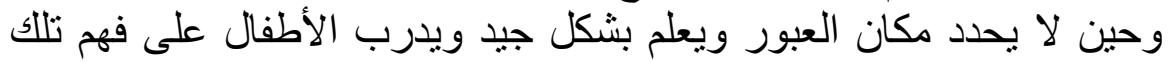

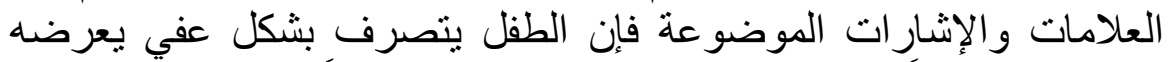

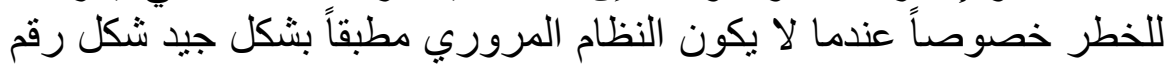
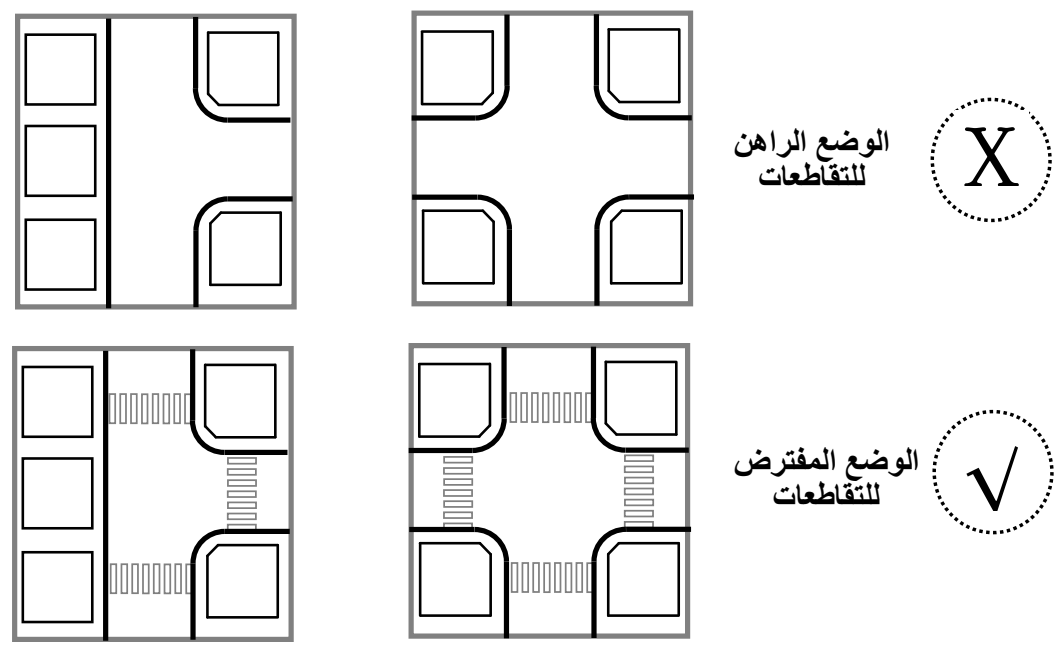

الشكل رقم (6) مسقط يوضح وضع الراهنل للتقاطعات في الأحياء السكنية وما تشكنه من خطورة على أمان الأطفال مقارنة بما يجب أن تكون عليه التقاطعات.

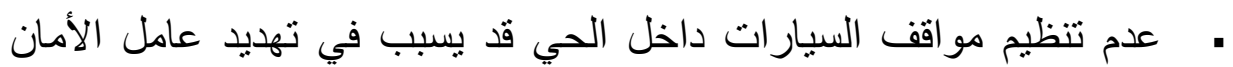

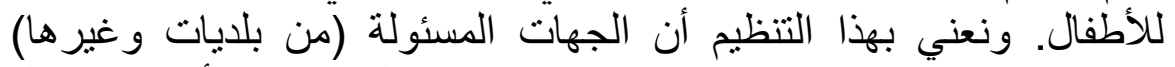

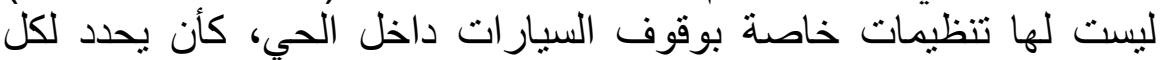

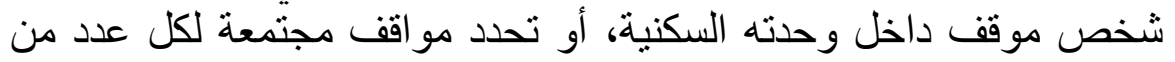

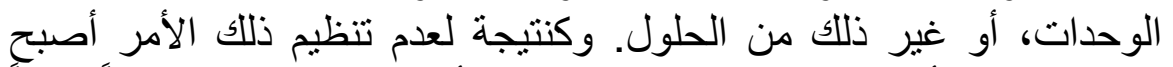

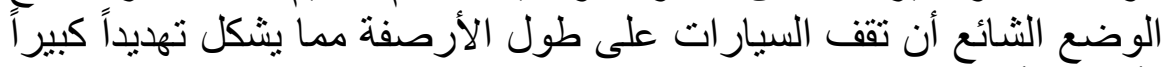

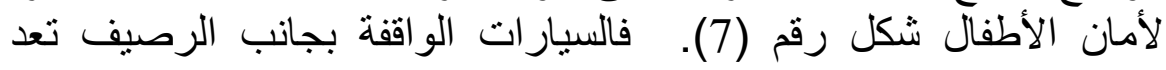




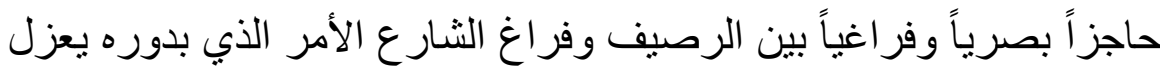

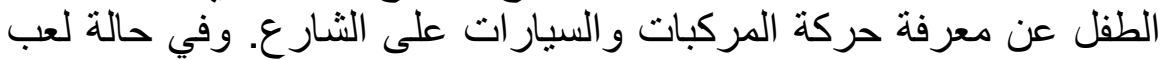

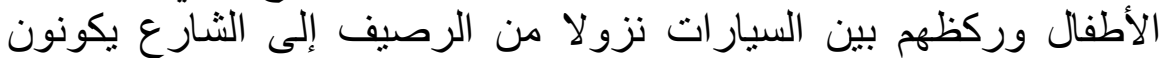

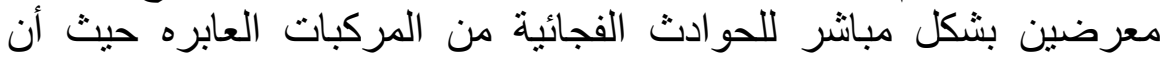

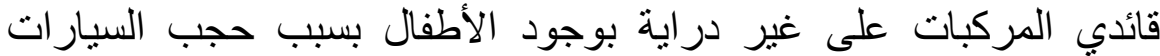

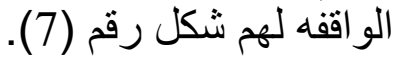
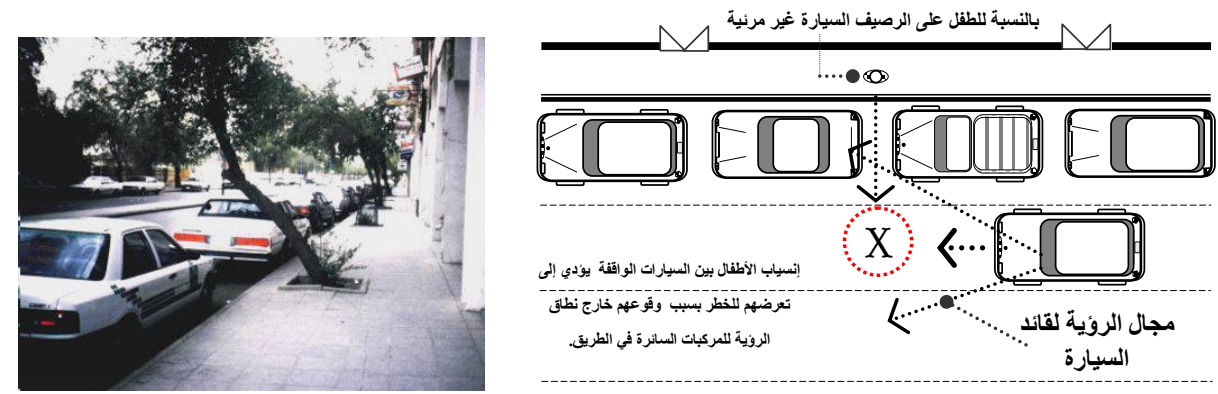

الثكل رقم (7) وقوف السيارات على طول الأرصفة الجانبية لشكل عامل تهديد لسلامة الأطفال بسبب حجب الروية بين الرصيف ومسار الطريق بالنسبة للأطفال ولقائدي

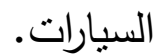

3-4 - تقسمات الأراضي وتصميم مخارج الوحدات السكنية: حسب نظام تقسيمات الأر اض المتبع في النظام الثبكي لتخطيط الأحياء السكنية

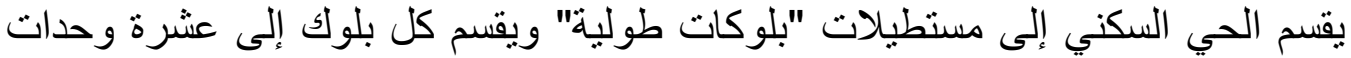

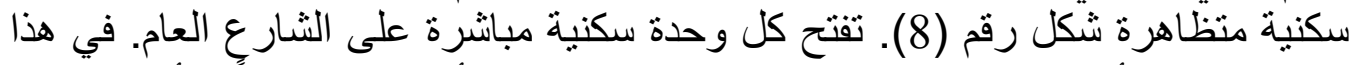

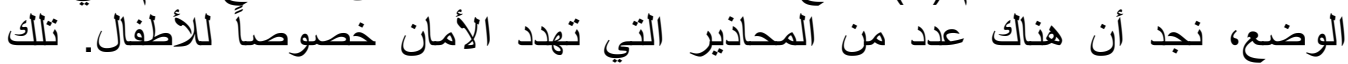
المحاذير هي:

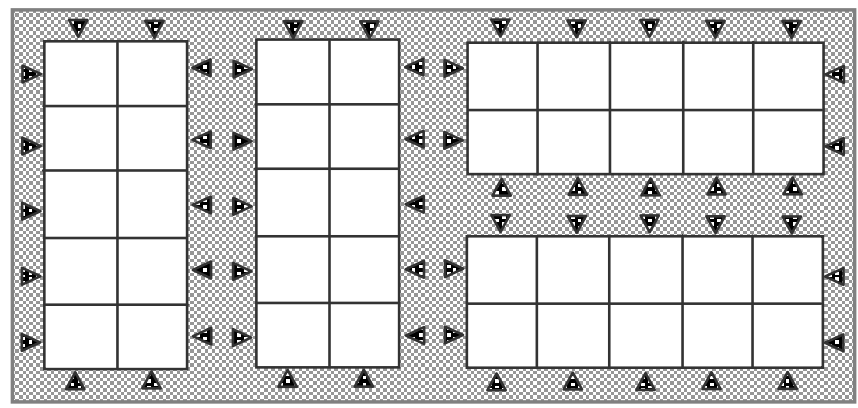

الثكل رقم (8) مسقط يوضح جزء من حي سكني يوضح تقسيمات الأراضي وفتحات الوحدات السكنية على الثارع العام. 


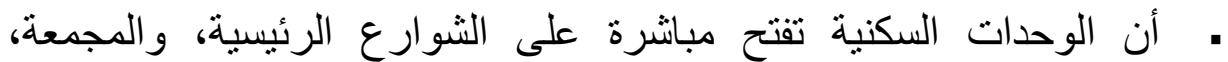

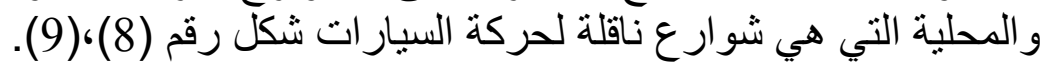

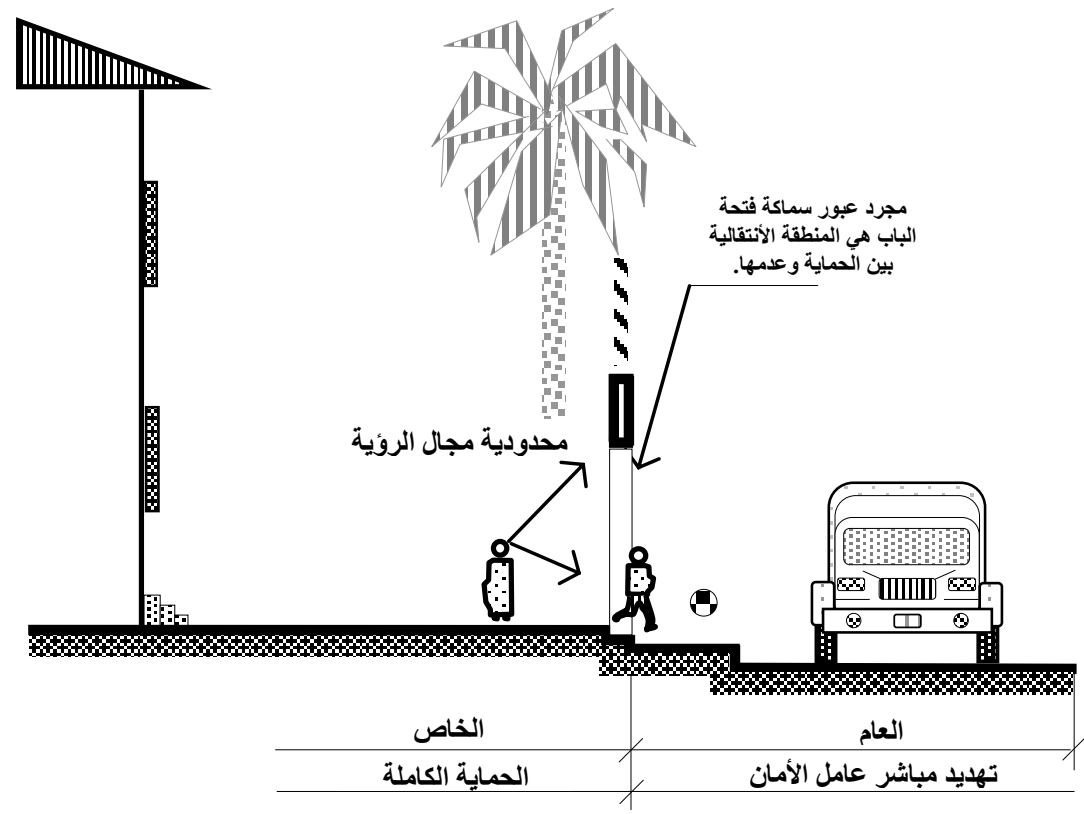

الثكل رقم 9: مسقط يوضح جزء من حي سكني يوضح تقسيمات الأراضي وفتحات الوحدات السكنية على الثشارع العام.

• ينتقل الطفل من فناء المنزل الأمامي الخاص جداً إلى فر اغ الثـار ع العام جداً

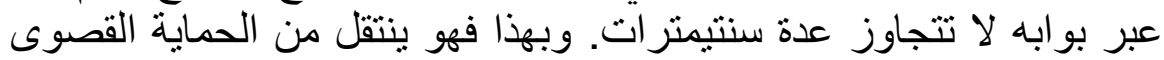

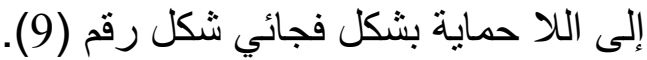

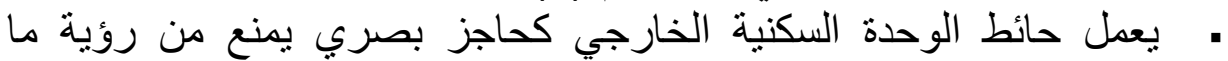

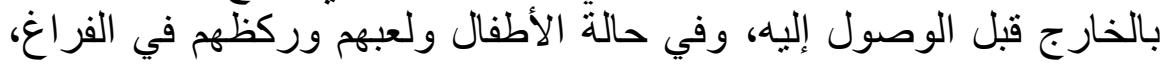

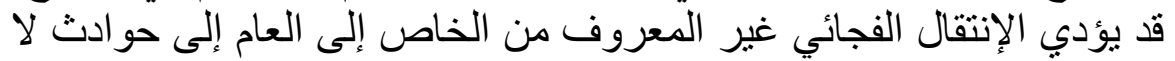

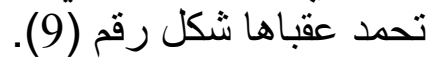

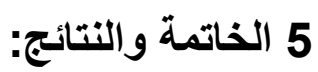

بالر غم من أن الأمان للمشاة مطلب لكل من بتو اجد على الثار ع سو اء كانِ ماثشياً

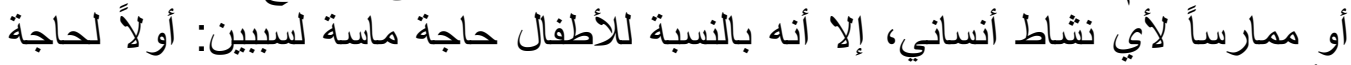

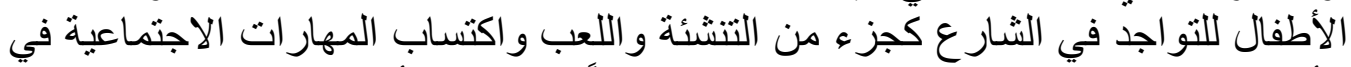

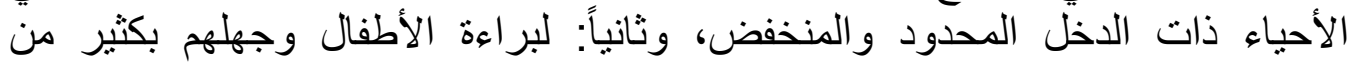

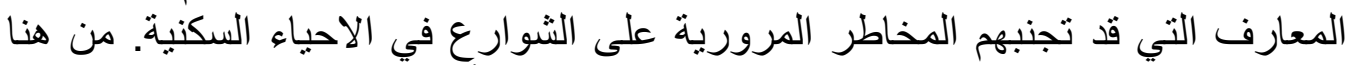

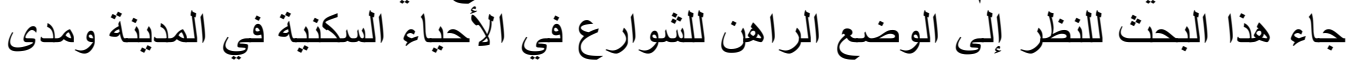


السلامة من الأخطار المرورية على الأطفال. لقد نظر البحث بتعمق لظروف واحتياجات

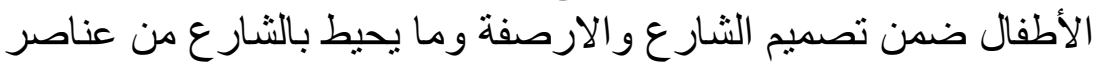

من الدراسة و التحليل في هذا البحث تم الخلوص إلى أن تخطيط وتصميم الثشارع

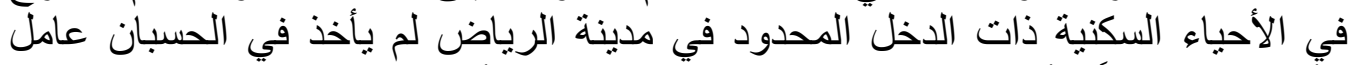

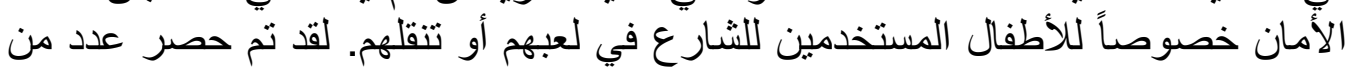

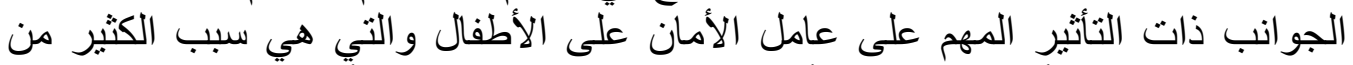

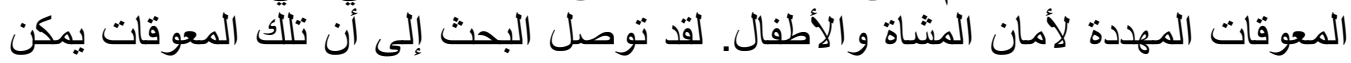

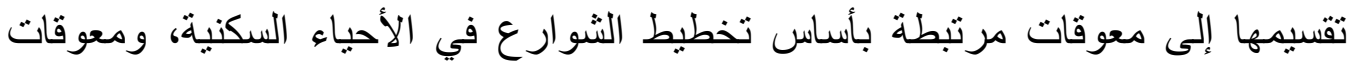

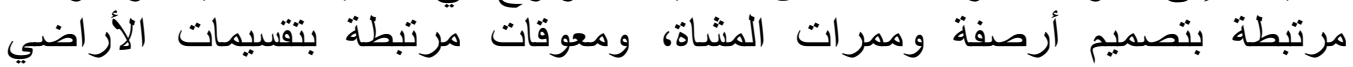
وتصميم فتحات الوحدات السكنية الخارجية.

إن عدم وجود فر اغات مناسبة للأطفال لممارسة أنشطتهم داخل الأحياء السكنية

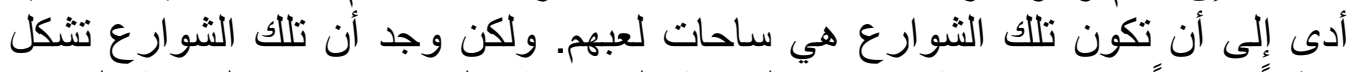

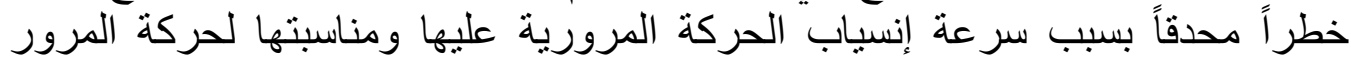

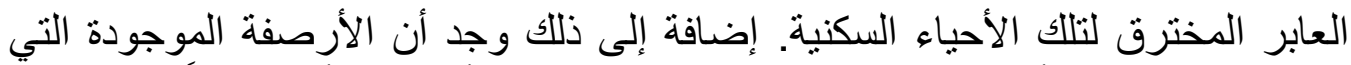

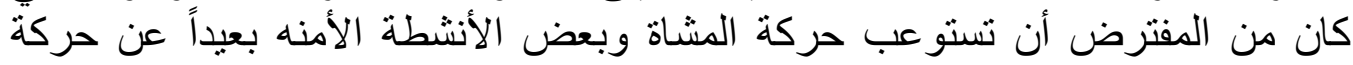

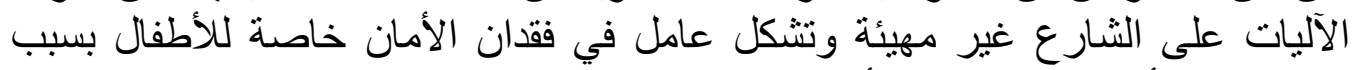

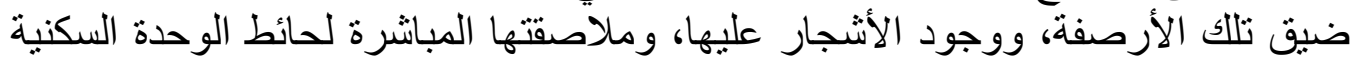

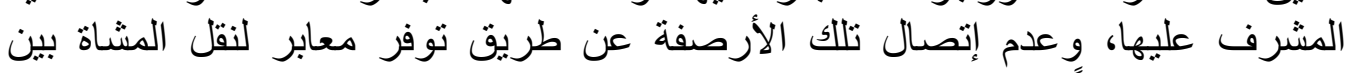

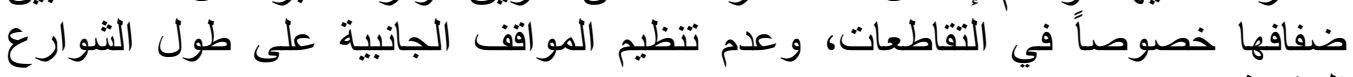
السكنية.

أيضاً تم التوصل إلى أن تقسيمات الأراضي وتصميم مخارج الوحدات السكنية

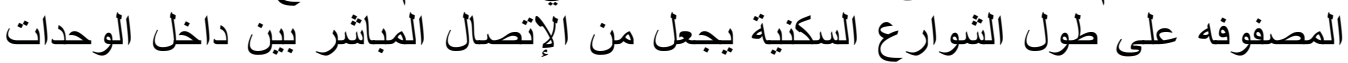

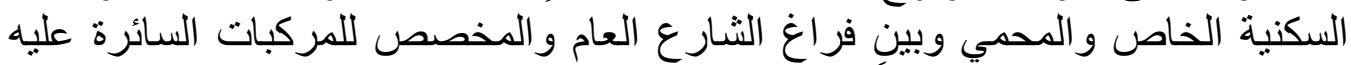

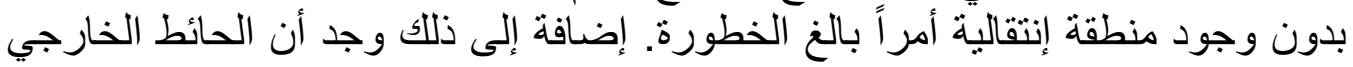

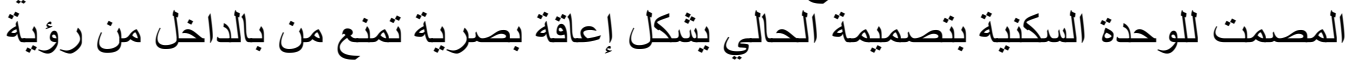
الثار ع مما يجعل النقلة بين الداخل و الخارج غامضة غلئة ومليئة بالمفاجئات.

إن الفائدة الأهم من هذا البحث هي توجيه الاهتمام إلى الحاجة الماسة لمر اعاة

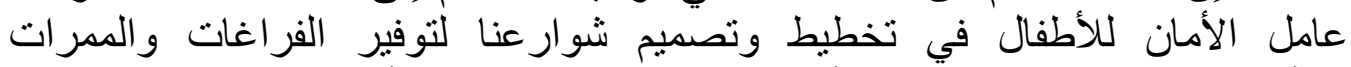

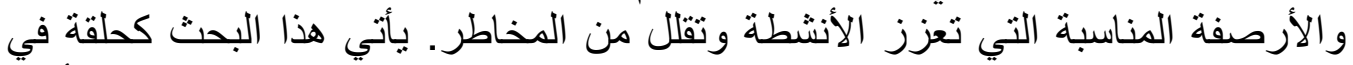

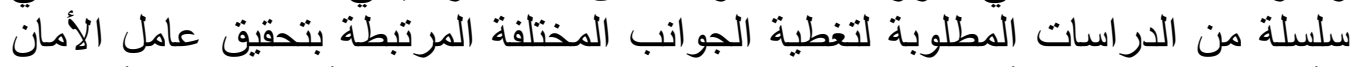
للأطفال في شوارع الأحياء السكنية حتى يمكن تحقيق بيئات سكنية أكثر سلامة وأمناء 
L. Mumford (1961), The City in History, Pelican, Harmondsworth.

D. King, S. Lawson, S. Prector, K. Johal, M. Hoyland (1987), "Child pedestrian accidents in inner areas: pattern and treatment". PTRC Summer Annual Meeting, Seminar, University of Bath, Septermperm 87.

F. Tibbalds (1992), Making People-Friendly Towns: Improving the public environment in towns and cities. Longman Group, Essex, England.

$$
\text { أمانة مدينة الرياض (1410 هـ). التشير الرينة الرياض التجميل في مدينة الرياض. أمانة. }
$$

R. O. Petch, and R. R. Henson (2000), "Child Road Safety in the Urban Environment Journal of Transport Geography, 8, 197-211.

C. Hass-Klau, G. Crampton, C. Dowland, and I. Nold (1999), Streets as Living Space-Helping Public Places Play their Proper Role: Good practice guidance with examples from a town centre study of European pedestrian behaviour. Landor Publishing Ltd, London.

F. A.. Mubarak (2004), "Urban growth boundary policy and residential suburbanization: Riyadh, Saudi Arabia". Habitat International, 28, 567-591.

B. Preston, (1976), Statistical Analysis of Child Pedestrian Accidents in Manchester and Salford. Machester Studies Publications, Manchester, UK.

Lars Leden, Per Garder, and Charlotta Jhonsson (2006), "Safe pedestrian crossings for children and elderly". Accident Analysis \& Prevention, 38, 289-294. 